\title{
SEWAGE SLUDGE MANAGEMENT FOR PHOSPHORUS \\ RECOVERY AS STRUVITE IN EBPR WASTEWATER TREATMENT
}

\section{PLANTS}

\author{
L. Pastor ${ }^{\mathrm{a}}$, N. Marti ${ }^{\mathrm{b}}$, A. Bouzas ${ }^{\mathrm{b}}$, A. Seco ${ }^{\mathrm{b}}{ }^{*}$ \\ ${ }^{a}$ Departamento de Ingeniería Hidráulica y Medio Ambiente. Universidad Politécnica de Valencia. Camino \\ de Vera s/n. 46022. Valencia. Spain. \\ bDepartamento de Ingeniería Química. Universidad de Valencia. Doctor Moliner 50. 46100. Burjassot. \\ Valencia. Spain.
}

\begin{abstract}
The influence of separate and mixed thickening of primary and secondary sludge on struvite recovery was studied. Phosphorus precipitation in the digester was reduced from $13.7 \mathrm{~g}$ of phosphorus per kg of treated sludge in the separate thickening experiment to 5.9 in the mixed thickening experiment. This lessening of the uncontrolled precipitation means a reduction of the operational problems and enhances the phosphorus availability for its later crystallization. High phosphorus precipitation and recovery efficiencies were achieved in both crystallization experiments. However, mixed thickening configuration showed a lower percentage of phosphorus precipitated as struvite due to the presence of high calcium concentrations. In spite of this low percentage, the global phosphorus mass balance showed that mixed thickening experiment produces a higher phosphorus recovery as struvite per kg of treated sludge (i.e., $3.6 \mathrm{gP} / \mathrm{kg}$ sludge vs. $2.5 \mathrm{gP} / \mathrm{kg}$ sludge in separate thickening).
\end{abstract}

\footnotetext{
* Corresponding author. Tel.: +34 9635443 26; fax: +34 963544898 E-mail address: aurora.seco@uv.es (A. Seco).
} 
Keywords

Anaerobic digestion; crystallization; phosphorus; struvite; wastewater.

Nomenclature

$\mathrm{COD}_{\mathrm{T}} \quad$ total chemical oxygen demand

EBPR enhanced biological phosphorus removal

ef effluent

in influent

ORGrel release from organic matter degradation

PAO polyphosphate accumulating organisms

PAOrel release from Poly-P hydrolysis

P-MAP phosphorus precipitated as struvite

Poly-P polyphosphate

prec precipitated

$\mathrm{P}_{\mathrm{T}} \quad$ total phosphorus concentration

Q volumetric flowrate

TOTrel total release

TS total solids

TVS total volatile solids

VFA volatile fatty acids 


\section{Introduction}

Water quality legislation has increased the standards regarding nutrient removal in order to overcome eutrophication problems in receiving waters. Moreover, phosphate rock is a finite resource thereby an efficient phosphorus recovery process should be promoted.

Phosphorus controlled crystallization as struvite appears to be a suitable method to recover this nutrient. Numerous studies have been reported in literature about phosphorus recovery (Battistoni et al., 2002; Parsons and Doyle, 2004; Stratful et al., 1999; von Münch et al., 2001) from wastewater as struvite. The reactors tested in these studies are mainly fluidised bed reactors or air agitated columns. They are operated either in continuous or batch mode, with seeding or without seeding. Several Other studies have shown that the product obtained can be used as an effective slow release fertilizer in agriculture (de-Bashan et al., 2004; Shu et al., 2006) and hence an economical benefit can be obtained.

Stabilisation of sludge at large wastewater treatment plants is usually carried out by anaerobic digestion. In this process, organic matter is transformed into $\mathrm{CH} 4$ and $\mathrm{CO} 2$ by the action of different groups of bacteria. The main advantages of this process are the reduction in the volume of waste sludge and the production of methane gas that can be utilized to supply energy. During anaerobic digestion of enhanced biological phosphorus removal (EBPR) sludges, most of the phosphorus stored as Poly-P and part of the phosphorus present in the organic matter is released. The rejected liquors from anaerobic digestion of enhanced biological phosphorus removal (EBPR) sludges show high phosphorus concentration which makes these streams very appropriate to recover 
phosphorus in a crystallization process. Other rejected liquors, as the thickener supernatant, could be also suitable for that process and should be also considered.

Since the struvite crystallization process is hardly affected by the composition of the crystallizer influent stream, the characteristics of the liquors employed must be studied. Hence, the sludge treatment line configuration turns into an important factor in the study because the characteristics of the liquors produced can be notably influenced by the configuration used. Moreover, the sludge treatment line configuration should be designed to avoid uncontrolled phosphorus precipitation in the digestion system and, consequently, to guarantee the highest quantity of phosphorus entering the crystallizer.

This work is part of a global research on phosphorus recovery in anaerobic digestion systems treating primary and EBPR sludge. In this paper, phosphorus recovery as struvite using the rejected liquors from two different configurations of the sludge line has been assessed.

\section{Methodology}

\subsection{Pilot plants description}

Four pilot plants located in Carraixet Wastewater Treatment Plant (Valencia) were used (Figure 1). These pilot plants were operated for fermentation and elutriation of primary sludge (plant 1), biological nitrogen and phosphorus removal (plant 2), anaerobic digestion of primary and secondary waste sludge (plant 3) and struvite crystallization (plant 4). The first two plants are described in Bouzas et al. (2007) and García-Usach et 
al. (2006), respectively. The primary and EBPR waste sludges produced in these two plants were use to feed the digestion pilot plant.

The anaerobic digestion pilot plant consists of a gravity thickener, an anaerobic digester and a secondary digester all of them built with polypropylene. The anaerobic digester is a completely mixed type reactor of 160 litres in effective volume. The content of the digester was completely mixed by the recirculation of the tank content using alternative pumped cycles. The reactor was equipped with $\mathrm{pH}$ and temperature electrodes. A data acquisition program was used to continuously store the monitored information of the process. Digested sludge was collected in the secondary digester for its later dewatering.

The crystallization pilot plant (Seco et al., 2004) consists of a 21 litre volume glass stirred reactor. The reactor is composed of two parts (Figure 2): a reaction zone and a settling zone to avoid driving fines particles with the effluent. The reaction zone was designed according to the typical dimensions of a perfectly mixed reactor (Mangin et al, 2004). The agitator is an axial flow profiled propeller (TT type from Mixel ${ }^{\circledR}$ company, France) equipped with three shaped blades. A second agitator was added at the extremity of the axis to avoid deposition at the bottom flow gate. The effluent flows out at the top of the settling zone over a weir. The reactor was equipped with conductivity, temperature and $\mathrm{pH}$ electrodes and a data acquisition program was also used to store these parameters. 


\subsection{Experimental procedure}

Two crystallization experiments were carried out using liquors coming from different sludge treatment line configurations (see Figure 1): separate thickening and mixed thickening of primary and EBPR sludges, treating 0.227 and $0.166 \mathrm{~kg}$ of sludge per day, respectively.

In the separate thickening configuration, the primary sludge is directly pumped from the primary settler/fermenter to the digester. Thickening of this sludge was not necessary due to the high solid concentrations achieved in the primary settling tank. Therefore, only the EBPR sludge (secondary sludge) was thickened. The thickener supernatant presented low phosphorus concentration and was directly recycled to the wastewater treatment line. Both sludges were fed to the anaerobic digester and then dewatered by centrifugation. The rejected liquor from centrifugation (Liquor A) was used as the unique substrate fed to the crystallizer.

In the mixed thickening configuration, the primary sludge and the EBPR sludge were co-thickened and elutriated. Primary sludge concentration was high enough for the anaerobic digestion system. However, it was thickened with the EBPR sludge in order to enhance the contact between both sludges. As in the previous configuration, the thickened sludges were fed to the anaerobic digester and afterwards dewatered by centrifugation. In this case, the thickener supernatant and the rejected liquor from the dewatering system were mixed (Liquor B) and afterwards employed as substrate for the crystallization plant. 
In both cases the anaerobic digestion was carried out at mesophilic conditions $\left(\mathrm{T}=35 \pm 1^{\circ} \mathrm{C}\right)$ and at a solids retention time of 20 days. The liquors obtained in each experiment were stored in a tank before their use in the crystallization process.

The crystallizer was operated in continuous mode for the liquid phase and in batchwise for the solid phase. The resulting hydraulic retention time in the reaction zone was 2.5 hours. The struvite precipitation process leads to a decrease in the $\mathrm{pH}$ value so $\mathrm{NaOH}$ was added in order to maintain the $\mathrm{pH}$ value in 8.7. Software based on fuzzy logic control was used to maintain the $\mathrm{pH}$ at the set value (Chanona et al., 2006).

\subsection{Experimental analysis}

Total phosphorus $\left(\mathrm{P}_{\mathrm{T}}\right)$, total chemical oxygen demand $\left(\mathrm{COD}_{\mathrm{T}}\right)$, total solids $(\mathrm{TS})$ and total volatile solids (TVS) analyses were performed in accordance with Standard Methods (APHA, 2005). $\mathrm{PO}_{4}-\mathrm{P}, \mathrm{NH}_{4}-\mathrm{N}$ and soluble calcium, magnesium and potassium were analysed by ion chromatography (Metrohm IC, Switzerland).

Precipitates obtained in the crystallizer were analyzed by X-ray diffraction (XRD) in order to check whether struvite crystals were formed. The XRD measurements were performed on a BRUKER AXS D5005 powder diffractometer. 


\section{Results}

Experimental characteristics of the main streams involved in the process (Figure 1) for experiment A and B are summarized in Table 1.

\subsection{Digestion process performance}

The average organic loading rate (OLR) during the experimental period was

1.0 \pm 0.1 gTVS/l for experiment A and $0.9 \pm 0.1$ gTVS/l for experiment $B$. The average values achieved for TVS removal and COD removal were around $53 \%$ and $61 \%$, respectively for experiment $\mathrm{A}$ and $59 \%$ and $66 \%$, respectively for experiment $\mathrm{B}$.

The specific gas production rate (SGP) was around 0.94 $\pm 0.27 \mathrm{l} / \mathrm{gTVS}$ rem and $1.01 \pm 0.21 \mathrm{l} / \mathrm{gTVS}$ rem for experiment A and B, respectively. A wide range of values in the biogas production was obtained as a consequence of the variation in the loading of volatile solids. Biogas composition was also determined obtaining $64 \pm 1 \%$ of $\mathrm{CH}_{4}$, $31 \pm 1 \%$ of $\mathrm{CO}_{2}, 4 \pm 1 \%$ of $\mathrm{N}_{2}$ and $1 \pm 0.5 \%$ of $\mathrm{SH}_{2}$ for experiment $\mathrm{A}$ and $63 \pm 1 \%$ of $\mathrm{CH}_{4}$, $31 \pm 1 \%$ of $\mathrm{CO}_{2}, 4 \pm 1 \%$ of $\mathrm{N}_{2}$ and $1 \pm 0.5 \%$ of $\mathrm{SH}_{2}$ for experiment $\mathrm{B}$, respectively.

Process stability in the digester was assessed by means of $\mathrm{pH}$, VFA concentration and alkalinity in the reactor. $\mathrm{pH}$ evolution was continuously monitored showing average values of 7 and 7,2 for experiment A and B, respectively. Total alkalinity (Alk $\mathrm{k}_{\mathrm{T}}$ ) was over $2000 \mathrm{mgCaCO}_{3} / \mathrm{l}$ throughout the two experimental periods, which is a reference value for a well-stabilized digester. The average ratio $\mathrm{Alk}_{\mathrm{VFA}} / \mathrm{Alk}_{\mathrm{T}}$ was $0.11 \pm 0.06$ and $0.21 \pm 0.13$ for experiment A and B, respectively. 


\subsection{Phosphorus precipitation in anaerobic digestion process}

Phosphorus (P), potassium (K), magnesium (Mg) and calcium (Ca) mass balances can be used to understand the chemical fixation mechanisms in the sludge treatment system. However, in order to perform these balances, several assumptions must be taking into account:

- Phosphorus stored as polyphosphate (Poly-P) is hydrolysed during anaerobic digestion (Wild et al., 1997).

- During Poly-P hydrolysis, the release of phosphorus is followed by a release of potassium and magnesium at the same ratio as it was observed during the phosphorus uptake (Jardin and Popel, 1994). Values of $0.354 \mathrm{gK} / \mathrm{gP}$ and 0.283 gMg/gP determined in previous studies (Barat et al., 2005) were used.

- There is no chemical fixation of the potassium released in the digester due to the high concentration of ammonium reached in it. Only in the case of low ammonium concentrations, different authors (Schuiling and Andrade, 1999 and Wilsenach et al., 2006) have pointed out that potassium struvite (K-MAP, $\mathrm{KMgPO}_{4} \cdot 6 \mathrm{H}_{2} \mathrm{O}$ ) could precipitate instead of ammonium struvite (MAP).

- Organic matter degradation produces a release of phosphorus, potassium, magnesium and calcium associated with the content of each element in the organic matter. This release must be quantified when the mass balances are performed.

\subsection{1. $\mathrm{P}, \mathrm{K}, \mathrm{Mg}$ and Ca content in the organic matter}


As said above, the release of $\mathrm{P}, \mathrm{K}, \mathrm{Mg}$ and $\mathrm{Ca}$ due to organic matter hydrolysis should be considered to properly perform the mass balances. This makes it necessary to determine the $\mathrm{P}, \mathrm{K}, \mathrm{Mg}$ and Ca content in the primary sludge and in the secondary sludge.

Experimental analyses of the primary sludge (data not shown) and previous studies on the process (Bouzas et al., 2007) were used to estimate P, K, and Mg content in the organic fraction of this sludge (Table 2). Calculations were made taking into account that the suspended $\mathrm{P}, \mathrm{K}$, and $\mathrm{Mg}$ were associated to organic matter. This assumption can be made since no precipitation of $\mathrm{P}, \mathrm{K}$, and $\mathrm{Mg}$ was found in the primary sludge. However, it is impossible to accurately determine the calcium content in the organic matter of primary sludge due to its the high inorganic calcium content in the sludge.

In the EBPR sludge, it is not possible to distinguish between the organic $\mathrm{P}, \mathrm{Mg}$, and $\mathrm{K}$ content and the content associated with Poly-P structure. Nevertheless, the organic matter in EBPR sludge is mainly biomass. Therefore, reported values for biomass composition (Metcalf and Eddy, 1991) were assumed in the EBPR sludge (Table 2).

In accordance with the previous discussion, the organic content of $\mathrm{P}, \mathrm{K}, \mathrm{Mg}$, and $\mathrm{Ca}$ in the mixed influent sludge was calculated using the proportion of primary and EBPR sludge used in each experiment (i.e., 44\% -56\% in experiment A and 45\%-55\% in experiment B, respectively) and the values shown in Table 2.

3.2.2. Mass balances in the digester. 
In accordance with the assumptions stated above and taking into account the average concentrations of the influent and effluent digester streams (streams 2 and 3 in Figure 1) mass balances were carried out in the anaerobic digester from the following equations.

- Phosphorus release by PAO bacteria (PPAOrel) (equation 1) was calculated from dissolved potassium mass balance (equation 2) bearing in mind the mass of potassium released per mass of phosphorus released.

$$
\begin{aligned}
& \mathrm{P}_{\text {PAOrel }}=\mathrm{K}_{\text {PAOrel }} / 0.354=\left(\mathrm{K}_{\text {TOTrel }}-\mathrm{K}_{\text {ORG rel }}\right) / 0.354 \\
& \mathrm{~K}_{\text {TOTrel }}=\mathrm{K}_{\text {ef }}-\mathrm{K}_{\mathrm{in}}
\end{aligned}
$$

- $\quad$ The precipitated phosphorus $\left(\mathrm{P}_{\mathrm{prec}}\right)$ was calculated from the dissolved phosphorus mass balance (equation 3).

$$
\mathrm{P}_{\text {prec }}=\mathrm{P}_{\text {in }}+\mathrm{P}_{\text {ORG rel }}+\mathrm{P}_{\mathrm{PAO}_{\text {rel }}}-\mathrm{P}_{\text {ef }}=\mathrm{P}_{\text {in }}+\mathrm{P}_{\text {TOT } \mathrm{rel}}-\mathrm{P}_{\text {ef }}
$$

- $\quad$ The precipitated magnesium (Mgrec) was calculated from the dissolved magnesium mass balance (equation 4). The amount of Mg released by PAO bacteria (MgPaOrel) was estimated as $0.283 \cdot P_{\text {PAOrel }}$.

$$
\mathrm{Mg}_{\text {prec }}=\mathrm{Mg}_{\text {in }}+\mathrm{Mg}_{\mathrm{ORG} \text { rel }}+\mathrm{Mg}_{\text {PAOrel }}-\mathrm{Mg}_{\text {ef }}=\mathrm{P}_{\mathrm{in}}+\mathrm{Mg}_{\mathrm{TOT} \text { rel }}-\mathrm{Mg}_{\text {ef }}
$$

- Finally, the dissolved calcium mass balance was carried out to calculate calcium precipitation in the digester (equation 5).

$$
\mathrm{Ca}_{\text {prec }}=\mathrm{Ca}_{\text {in }}+\mathrm{Ca}_{\mathrm{ORG} \text { rel }}-\mathrm{Ca}_{\mathrm{ef}}
$$

The mass balance results for experiments A and B are shown in Table 3. As can be seen, experiment A shows a higher phosphorus precipitation than experiment B (460.4 
mg/l in A vs. $229.0 \mathrm{mg} / \mathrm{l}$ in B). Comparing the sludge handling of primary and EBPR sludge before entering the digester, the main difference between both experiments is the operation of the thickening stage. As it will be discussed later, the separate and mixed thickening of the two sludges strongly affects the precipitation of phosphorus in the digester. As can be also observed in Table 3, a higher precipitation of magnesium and a slightly higher precipitation of calcium were obtained in the anaerobic digester during the experiment $\mathrm{A}$.

\subsection{Phosphorus precipitation in crystallization process}

As can be seen in Table 1 (stream 4), the two liquors used to feed the crystallizer showed quite different characteristics.

Liquor A presented higher phosphorus, ammonium and potassium concentrations than Liquor B. However, the calcium concentration in Liquor A is lower than in Liquor B. The molar ratios between the main components of the liquor stream (i.e. phosphorus, ammonium, magnesium and calcium) have an important effect on the crystallization process. As the Mg:P molar ratio in Liquor A did not satisfy the stoichiometric requirement for struvite precipitation (i.e., 1:1), extra magnesium dose was needed. In Liquor B no magnesium addition was necessary. The required magnesium addition in Liquor $\mathrm{A}$ and the $\mathrm{NaOH}$ addition needed to adjust the $\mathrm{pH}$ in both experiments modified the molar ratios in the crystallizer inlet stream. The resulting phosphorus concentration and molar ratios values are reported in Table 4. 
The phosphorus precipitation in the crystallizer was assessed taking into account two types of efficiencies: recovery efficiency (equation 6) and precipitation efficiency (equation 7). The precipitation efficiency represents the process efficiency from a thermodynamic point of view provided that the supersaturation can be almost completely consumed, which should be the case with sufficient residence time. The recovery efficiency takes into account both the precipitation and crystal growth efficiency.

Recovery Effiency $=\frac{\mathrm{P}_{\text {Tin }}-\mathrm{P}_{\text {Tef }}}{\mathrm{P}_{\text {Tin }}} \cdot 100$

Precipitation Efficiency $=\frac{\mathrm{PO}_{4}-\mathrm{P}_{\mathrm{in}}-\mathrm{PO}_{4}-\mathrm{P}_{\mathrm{ef}}}{\mathrm{PO}_{4}-\mathrm{P}_{\mathrm{in}}} \cdot 100$

As can be seen in Table 5, high phosphorus precipitation efficiencies were obtained in both experiments: $91.1 \%$ and $83.1 \%$ for Liquor A and B, respectively. The recovery efficiencies showed slightly lower values (83.9\% and 76.0\% for Liquor A and B respectively) than the precipitation ones. Differences between the two parameters are attributed to the formation of fine crystals that are driven out with the effluent and consequently can not be recovered.

According to the literature (Musvoto et al., 2000), struvite precipitates at neutral and higher $\mathrm{pH}$ and at $\mathrm{Mg} / \mathrm{Ca}$ molar ratios higher than 0.6. Therefore, at the crystallizer $\mathrm{pH}$, it can be considered that all magnesium precipitated as struvite (see Table 5). Hence, 72.6 $\%$ and $35.4 \%$ of phosphorus precipitation as struvite (P-MAP) was obtained for Liquors A and B, respectively. Struvite presence in the recovered solid was confirmed 
by means of XRD analyses. Figure 3 shows the typical struvite diffraction peaks for both experiments.

Nevertheless, considering the magnesium removal in the crystallizer, more phosphorus precipitation than the required to struvite formation was obtained in both experiments. This indicates that other phosphate salts, as well as struvite, precipitate in the crystallizer. Precipitation of calcium phosphates was considered since soluble calcium showed a significant decreased in the crystallizer.

Microscopic pictures of samples taken from the crystallizer reaction zone in both experiments were taken are shown in Figure 4. Typical struvite crystals were can be observed in both pictures. However, higher density of struvite crystals was observed in the experiment conducted with Liquor A than in the one with Liquor B. These results are in agreement with the P-MAP percentages obtained in each experiment. In liquor B was In Figure 4, it can be also observed a mass of other compound among the struvite crystals which could be amorphous calcium phosphate or just organic matter.

\section{Discussion}

With regard to the anaerobic digestion process performance, a high TVS and COD removal was achieved in both experiments when compared with the typical values observed in anaerobic mesophilic digesters treating mixed sludges [18]. This fact was attributed to the high mixing power provided by the agitation pump, $0.1 \mathrm{~W} / \mathrm{l}$. Typical values for the power input required for mechanically mixed anaerobic digesters are in the range $0.005-0.008 \mathrm{~W} / \mathrm{l}$ for normal agitation and $0.02 \mathrm{~W} / \mathrm{l}$ for high agitation [18]. The 
high mixing power used in this experiment may cause higher bacterial structure destruction, thereby increasing volatile solid removal.

The specific gas production rate (SGP) was in agreement with the literature data of 1 l/gTVSrem observed when digesting primary and secondary sludges. Biogas composition showed also a typical value found for proper anaerobic digestion processes.

With regard to the anaerobic digestion process performance the organic matter removal was high when compared with the typical values observed in anaerobic mesophilic digesters treating mixed sludges [18]. Moreover, a higher TVS and COD removal was achieved in experiment B than in experiment A. This fact was attributed to the higher mixing power provided by the agitation pump in experiment $\mathrm{B}(0.36 \mathrm{~W} / \mathrm{l})$ than in experiment $\mathrm{A}(0.11 \mathrm{~W} / \mathrm{l})$. The high mixing power used in experiment $\mathrm{B}$ may cause higher bacterial structure destruction, thereby increasing volatile solid removal. Typical values for the power input required for mechanically mixed anaerobic digesters are in the range $0.005-0.008 \mathrm{~W} / \mathrm{l}$ for normal agitation and $0.02 \mathrm{~W} / \mathrm{l}$ for high agitation [18].

The specific gas production rate (SGP) in both experiments was in agreement with the literature data of 1 l/gTVS rem observed when digesting primary and secondary sludges. Biogas composition showed $64 \% \pm 1$ of methane content in experiment $\mathrm{A}$ and $63 \% \pm 1$ in experiment B, typical values found for proper anaerobic digestion processes. 
Experiment A shows higher phosphorus precipitation inside the digester than experiment B. This can be attributed to the different sludge handling before the digestion stage in the two experiments.

Separated thickening of sludges (experiment A) does not enhance Poly-P hydrolysis due to the lack of the high concentration of VFA that primary sludge provides. Therefore, a high concentration of phosphorus is released in the digester, from organic solid degradation and from Poly-P hydrolysis. This phosphorus release increases the phosphorus potential to precipitate inside the digester as magnesium and calcium phosphates. In experiment A, $13.7 \mathrm{~g}$ of phosphorus per $\mathrm{kg}$ of treated sludge precipitated. However, in experiment B only 5.9 g of phosphorus per kg of treated sludge precipitated.

Mixed thickening of sludges (experiment B) reduces the phosphorus release in the digester since Poly-P hydrolysis begins in the thickener. This can be proved comparing the potassium released by PAO bacteria in the digester for both experiments (134.3 mg/l in experiment A vs. $3.9 \mathrm{mg} / \mathrm{l}$ in experiment B). These results show that nearly all the Poly-P is hydrolysed in the gravity thickener. Moreover, the elutriation of the thickened sludge favoured the extraction of the released phosphorus through the thickener supernatant. This gives rise to a high phosphorus concentration stream that can be used in the phosphorus recovery process as struvite.

The higher magnesium precipitated in experiment A can also be put down to the separate thickening of both sludges, since Poly-P hydrolysis occurs mainly in the 
digester. Therefore, experiment A shows a higher dissolved magnesium concentration available to precipitate in the digester.

Calcium precipitation was slightly higher in experiment A. This can be explained by the higher soluble phosphorus concentration inside the digester in this experiment, which promotes the formation of calcium phosphates.

In the crystallization process high phosphorus precipitation efficiency (above 80\%) was obtained in both experiments. However, regarding the phosphorus precipitated in the crystallizer as struvite, Liquor B produced a significantly low percentage (35.4\%) compare to the value obtained with Liquor A (72.6\%). The low struvite percentage obtained with Liquor B was attributed to the higher Ca:Mg molar ratio in the crystallizer inlet stream which favoured the calcium phosphate formation.

The influence of calcium on struvite crystallization from a synthetic supernatant has been experimentally studied by several authors (Le Corre et al., 2005; Wang et al., 2005; Pastor et al., submitted). Le Corre et al. (2005) showed that the increase in calcium concentrations inhibited struvite growth: at Ca:Mg molar ratio of 0.5 an amorphous calcium phosphate precipitated on struvite surface, affecting its growth; besides, from molar ratios Ca:Mg above 1 the formation of an amorphous precipitate rather than crystalline struvite was found. Pastor et al. (submitted) obtained $42 \%$ of phosphorus precipitated as struvite using molar ratios Ca:Mg of 1 . This percentage decreased until 8\% when the molar ratio Ca:Mg was approximately 1.9. In the present work, Liquor B showed a molar ratio Ca:Mg of 1.6. This value accounts for the lower 
struvite formation obtained in that experiment compared with the one employing Liquor A (Ca:Mg of 0.4).

Several calcium phosphates can be formed in aqueous solution. Among them, the most common are amorphous calcium phosphate (ACP), dicalcium phosphate dehydrate (DCPD), octacalcium phosphate (OCP) and hidroxylapatite (HAP). XRD analyses were used to determine whether any crystalline calcium phosphate was present. The XRD analysis of the recovered solids at the end of the experiments showed that none of the crystalline calcium phosphates mentioned above were recovered. XRD results with hydroxylapatite pattern for both experiments are shown as an example in Figure 5. These results suggested that the calcium phosphate precipitated was an amorphous calcium phosphate.

Considering the final sludge disposal, the higher precipitation in the digester in experiment A leads to a higher volume of sludge to be disposed, with the consequent costs increase. Moreover, the uncontrolled precipitation in the digester leads to operational problems related to pipes and equipment blockages increasing the time and cost of maintenance at the plant. Furthermore, the higher magnesium precipitation reduces the concentration of this ion in the stream fed to the crystallization reactor, being necessary an extra dose of magnesium in the crystallizer. As mentioned before, no extra dose of magnesium was needed in experiment B, reducing the operational costs in the crystallization process. 
However, from the struvite production point of view, experiment A shows a higher percentage of phosphorus precipitated as struvite (Table 4 5). According to this, the separate thickening configuration seems to be the more suitable for obtaining struvite than the mixed thickening configuration. Nevertheless, the phosphorus recovery as struvite must be considered from a global point of view taking into account the whole sludge treatment line. In this way, a phosphorus mass balance was performed for the two sludge line configurations. In spite of the low P-MAP percentage in experiment B, 3.6 grams of phosphorus precipitated as struvite per kg of treated sludge were obtained. In the experiment A, only 2.5 grams per kg of treated sludge were obtained. This difference is mainly as a consequence of the high thickener effluent flow rate employed in the crystallizer in experiment B.

\section{Conclusions}

Mixed thickening of primary and EBPR sludge reduces precipitation in the digester due to the enhancement of Poly-P hydrolysis in the thickener. This strategy makes it possible to decrease the sludge volume to be disposed and to control pipes and equipment blockages. Therefore, maintenance costs in the plant can be reduced. Moreover, elutriation of the thickened sludge favours the extraction of the released phosphorus through the thickener supernatant, making this stream very suitable for the crystallization process. This suitability is accompanied with a reduction in the use of reactives since magnesium addition to precipitate struvite was no needed.

Although high phosphorus precipitation and recovery efficiencies have been achieved with both liquors studied, Liquor B showed a lower percentage of phosphorus 
precipitated as struvite than Liquor A. This is due to the high calcium concentrations entering the crystallizer which lead to the formation of calcium phosphates. However, in spite of this low P-MAP percentage, the global phosphorus mass balance indicated that mixed thickening configuration produces a higher phosphorus recovery as struvite per kg of treated sludge.

Summing up, phosphorus recovery as struvite requires not only the optimization of the crystallization process, but also the management optimization of the sludge treatment line. Future investigations will focus in the sludge line management strategy in order to improve the phosphorus recovery by struvite crystallization.

\section{Acknowledgements}

This research work has been supported by the Spanish Research Foundation (MCYT, project PPQ2002-04043-C02-02), which is gratefully acknowledged. Technical support from Entidad Pública de Saneamiento de Aguas Residuales de la Comunidad Valenciana is also gratefully acknowledged.

\section{References}


APHA, 2005. Standard Methods for the Examination of Water \& Wastewater. $21^{\text {th }}$ ed. American Public Health Association, American Water Works Association and Water Environment Federation, Washington DC, USA.

Barat, R., Montoya, T., Seco, A., Ferrer, J., 2005. The role of potassium, magnesium and calcium in the enhanced biological phosphorus removal treatment plants. Environ. Technol.., 26, 983-992.

Battistoni, P., De Angelis, A., Prisciandaro, M., Boccadoro, R., Bolzonella, D., 2002. P removal from anaerobic supernatants by struvite crystallization: long term validation and process modelling. Water Res., 36, 1927-1938.

Bouzas, A., Ribes, J., Ferrer, J. Seco, A., 2007. Fermentation and elutriation of primary sludge: Effect of SRT on process performance. Water Res., 41, 747-756.

Chanona, J., Pastor, L., Borrás, L., Seco, A., 2006. Application of a Fuzzy algorithm for pH control in a Struvite Crystallization Reactor. Water Sci. Technol. 53 (12), 161168.

de-Bashan, L.E., Bashan, Y., 2004. Recent advances in removing phosphorus from wastewater and its future use as fertilizer (1997-2003). Water Res. 38 (19), 42224246.

Garcia-Usach, F., Ferrer, J., Bouzas, A., Seco, A., 2006. Calibration and simulation of ASM2d at different temperatures in a phosphorus removal pilot plant. Water Sci. Technol. 53 (12), 199-206.

Jardin, N. and Pöpel, H.J., 1994. Phosphate release of sludges from enhanced biological P-removal during digestion. Water Sci. Technol., 20(6), 281-292.

Le Corre, K.S., Valsami-Jones, E., Hobbs, P., Parsons, S.A., 2005. Impact of calcium on struvite crystal size, shape and purity. J. Cryst. Growth, 283 (3-4), 514-522. 
Mangin, D., Klein, J.P., 2004. Fluid dynamic concepts for a phosphate precipitation reactor design, in: Phosphorus in Environmental Technologies: Principles and Applications, E. Valsami Jones, IWA publishing, London, UK, pp. 358-401.

Metcalf and Eddy Inc., 1991. Wastewater engineering: treatment, disposal and reuse McGraw-Hill, Inc. New York.

Musvoto, E.V., Wentzel, M.C., Ekama, G.A., 2000. Integrated chemical-physical processes modelling-II. Simulating aeration treatment of anaerobic digester supernatants. Water Res., 34, 1868-1880.

Parsons, S.A., Doyle, J.D., 2004. Struvite scale formation and control. Water Sci. Technol. 49 (2), 177-182.

Pastor, L., Mangin, D., Barat, R., Seco, A. Phosphorus recovery in wastewater through a precipitation process: effect of the operational parameters. Submitted to Chem. Eng. $J$.

Schuiling, R.D., Andrade, A., 1999. Recovery of struvite from calf manure. Environ. Technol. 20 (7), 765-768.

Seco, A., Pastor, L., Barat, R., Ferrer, J., Mangin, D., 2004. Nutrient recovery by struvite crystallization: and improvement for enhanced biological phosphorus removal treatment plants. In proceeding of: International Conference on wastewater treatment for nutrient removal and reuse, Asian Institute of Technology, Thailand, 26-29 January, 1, 117-124.

Stratful, S., Brett, S., Scrimshaw, M. B. and Lester, J.N., 1999. Biological phosphorus removal, its role in phosphorus recycling. Environ Technol., 20, 681-696. 
Shu, L., Schneider, P., Jegatheesan, V., Johnson, J., 2006. An economic evaluation of phosphorus recovery as struvite from digester supernatant. Bioresour. Technol. 97 (17), 2211-2216.

von Münch, E. and Barr, K., 2001. Controlled struvite crystallization for removing phosphorus from anaerobic digester sidestreams. Wat. Res., 35, 151-159.

Wang, J. Burken, J.G., Zhang, X., and Surampalli, R., 2005. Engineered Struvite Precipitation: Impacts of component-ion molar ratios. Journal of Environmental Engineering, 131 (10), 1433-1440.

Wild, D., Kisliakova, A., Siegrist, H., 1997. Prediction of recycle phosphorus loads from anaerobic digestion. Water Res. 31 (9), 2300-2308.

Wilsenach, J., Schuurbiers, C.A.H., van Loosdrecht, M.C.M., 2006. Phosphate and potassium recovery from source separated urine through struvite precipitation. Water Res., 41, 458-466. 
Figure 1 Schematic layout of the pilot plants

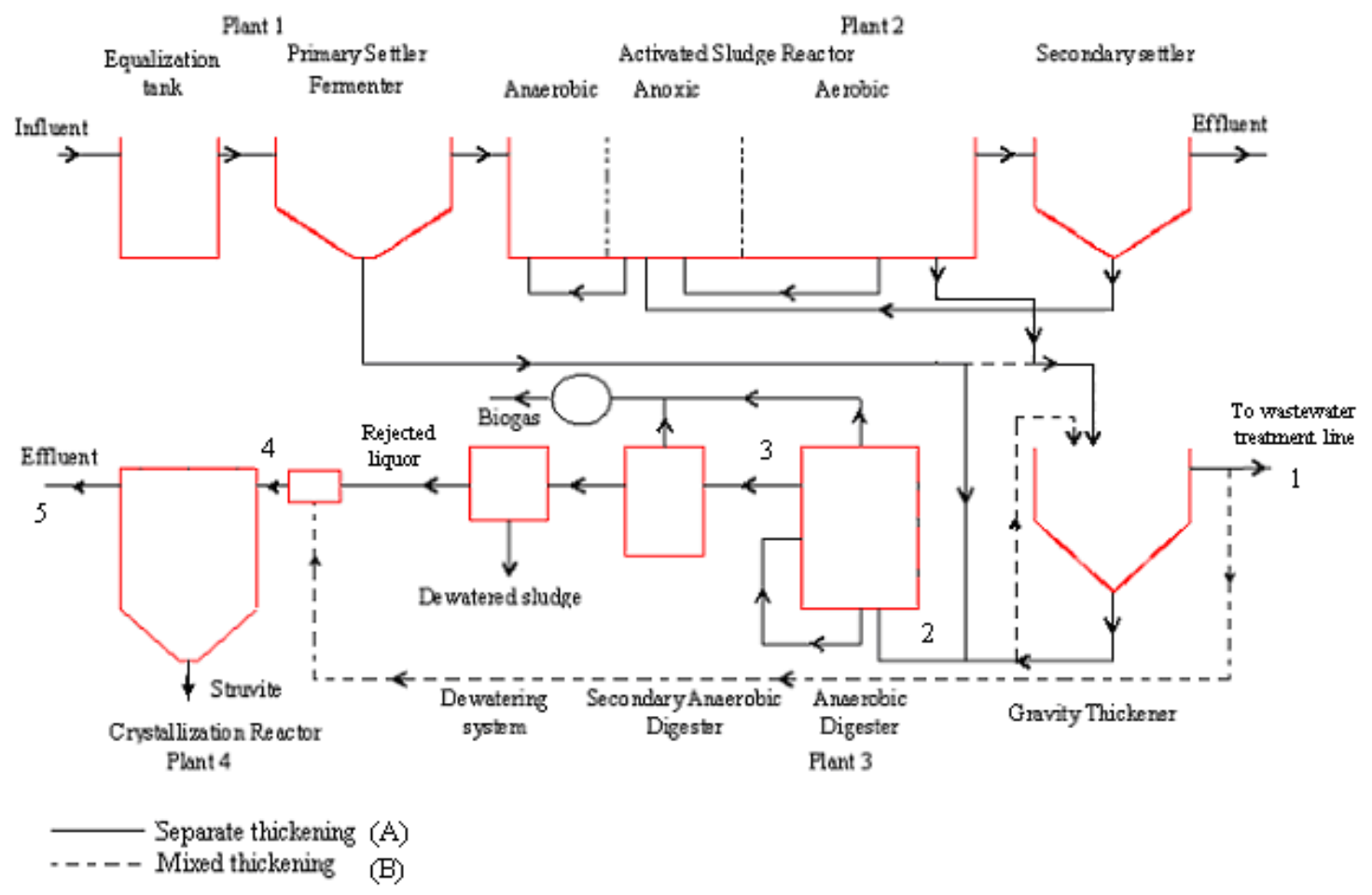


Figure 2 Schematic layout of crystallization pilot plant

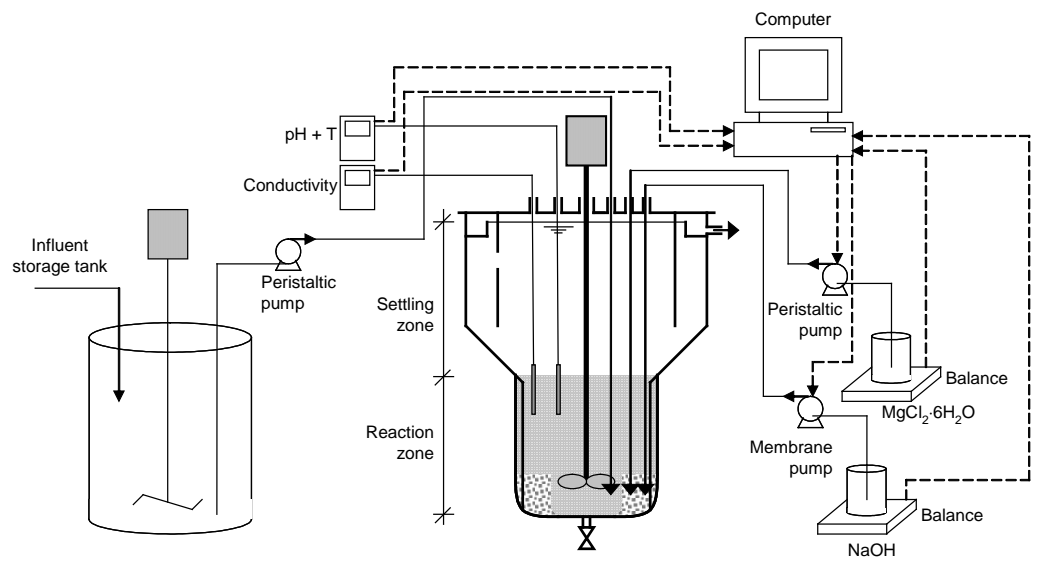


Figure 3 XRD analyses of the crystallization recovered product for Liquor A and B (Struvite pattern)
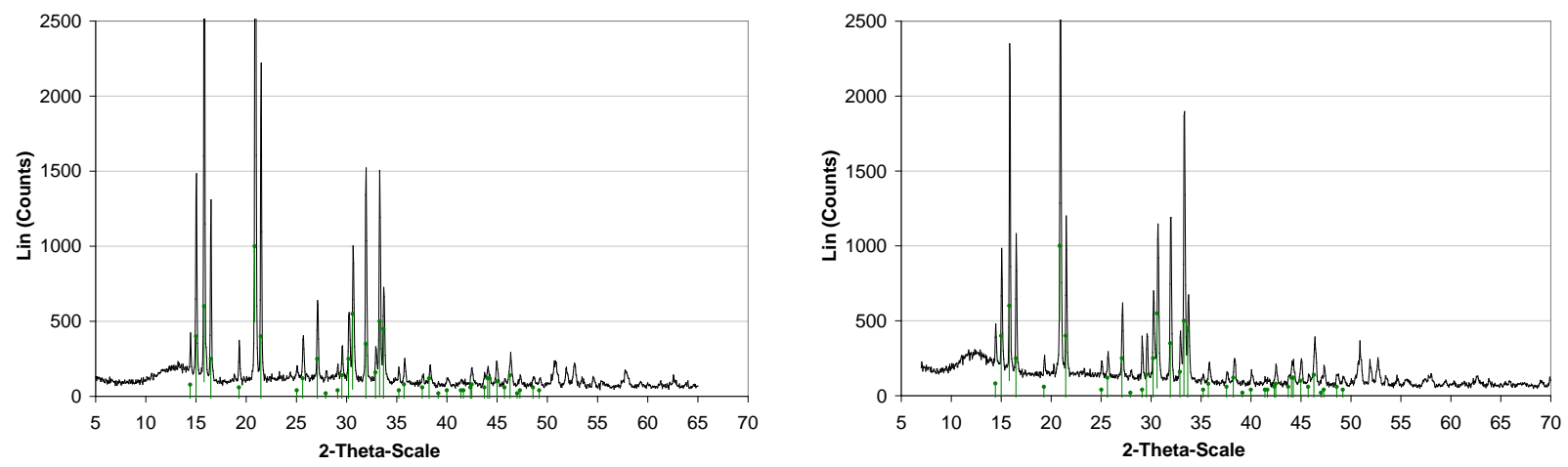

Liquor A

Liquor B

— Type: 2th/Th locked - Start: $5.000^{\circ}$ - End: $65.000^{\circ}$ - Step: $0.050^{\circ}$ - Step time: 3 . s - Temp: $25^{\circ} \mathrm{C}$ (Room) - Time Started: $20 \mathrm{~s}$ - 2-Theta: $5.000^{\circ}$ Theta: $2.500^{\circ}-$ Phi: $0.00^{\circ}$

- 15-0762 (*)-Struvite, syn-NH4MgPO4.6H2O-Y:50.00\%- d x by:1.- WL: 1.54056 -Orthorhombic -a 6.945-b 11.208-c 6.1355-alpha 90.000-beta 90.000-gamma 90.000-Primitive-Pm21n(31)-2-477.585 - 1/lc 
Figure 4 Microscopic pictures (4x). Samples from the reaction zone

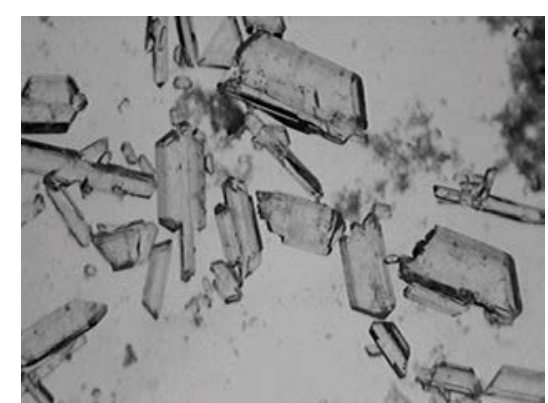

Liquor A

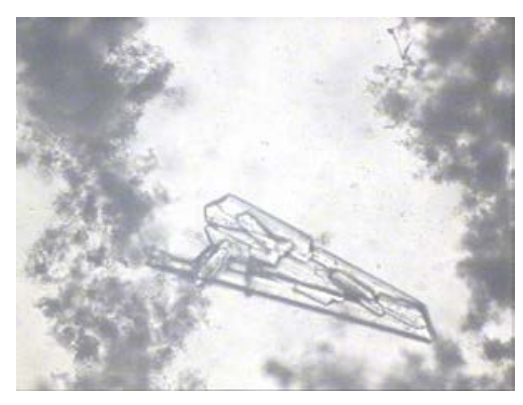

Liquor B 
Figure 5 XRD analyses of the crystallization recovered product for Liquor A and B (Hydroxylapatite pattern)
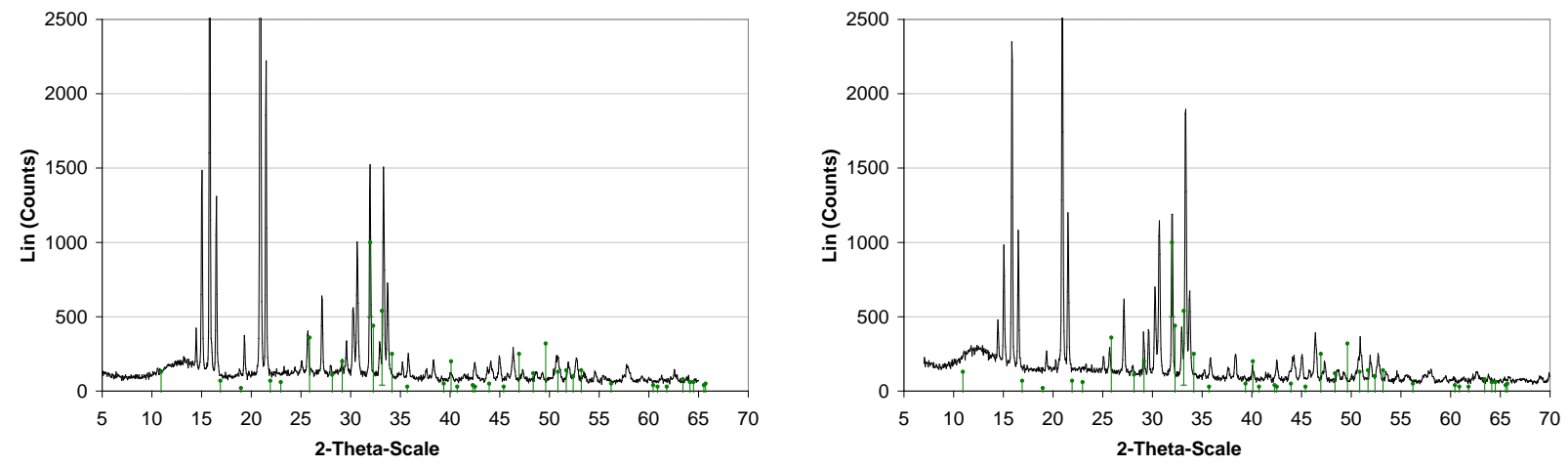

Liquor A

Liquor B

— Type: 2 th/Th locked - Start: $5.000^{\circ}$ - End: $65.000^{\circ}$ - Step: $0.050^{\circ}$ - Step time: $3 . \mathrm{s}$ - Temp: $25^{\circ} \mathrm{C}$ (Room) - Time Started: $20 \mathrm{~s}$ - 2-Theta: $5.000^{\circ}$ Theta: $2.500^{\circ}-$ Phi: $0.00^{\circ}$

- 73-1731 (C) - Hydrxylapatite - Ca5(PO4)3(OH) - Y: 50.00 \% - d x by: 1. - WL: 1.54056 - Hexagonal - a 9.40000 - b 9.40000 - c 6.93000 - alpha 90.000 - beta 90.000 - gamma 120.000 - Primitive - P63/m (176) - 2 -530.29 
Table 1 Experimental data of the pilot plant main streams

\begin{tabular}{|c|c|c|c|c|c|c|c|c|c|c|c|}
\hline \multirow{2}{*}{\multicolumn{2}{|c|}{ Parameter }} & \multicolumn{5}{|c|}{ Experiment A } & \multicolumn{5}{|c|}{ Experiment B } \\
\hline & & 1 & 2 & 3 & 4 & 5 & 1 & 2 & 3 & 4 & 5 \\
\hline $\mathrm{Q}$ & $(\mathrm{l} / \mathrm{d})$ & 41.25 & 6.75 & 6.75 & 4.50 & 4.50 & 43.75 & 4.25 & 4.25 & 47.35 & 47.35 \\
\hline $\mathrm{PO}_{4}-\mathrm{P}$ & (mg/l) & 11.3 & 51.0 & 188.9 & 167.1 & 13.2 & 46.5 & 98.6 & 67.6 & 43.6 & 7.3 \\
\hline $\mathrm{NH}_{4}-\mathrm{N}$ & (mg/l) & 10.9 & 64.0 & 536.0 & 609.8 & 469.1 & 24.8 & 110.6 & 796.0 & 130.9 & 123.1 \\
\hline $\mathrm{Mg}^{2+}$ & (mg/l) & NA & 61.6 & 27.0 & 29.2 & 12.3 & 57.2 & 72.3 & 40.4 & 50.5 & 39.8 \\
\hline $\mathrm{Ca}^{2+}$ & (mg/l) & NA & 117.0 & 21.5 & 79.6 & 60.5 & 157.5 & 124.7 & 57.0 & 131.8 & 71.0 \\
\hline $\mathrm{K}^{+}$ & (mg/l) & NA & 49.6 & 245.6 & 241.0 & 217.7 & 24.9 & 69.5 & 97.3 & 35.9 & 36.2 \\
\hline TS & $(\mathrm{mg} / \mathrm{l})$ & NA & 29251 & 16000 & NA & NA & NA & 29583 & 16850 & NA & NA \\
\hline TVS & (mg/l) & NA & 20170 & 9374 & NA & NA & NA & 18637 & 7545 & NA & NA \\
\hline $\mathrm{COD}_{\mathrm{T}}$ & (mg/l) & NA & 38363 & 14976 & NA & NA & NA & 32650 & 11076 & NA & NA \\
\hline $\mathrm{P}_{\mathrm{T}}$ & $(\mathrm{mg} / \mathrm{l})$ & NA & 1020.0 & 985.0 & 175.6 & 25.2 & NA & 577.0 & 443.0 & 55.2 & 12.7 \\
\hline $\mathrm{pH}$ & & NA & 6.6 & 7.0 & NA & 8.7 & NA & 6.2 & 7.2 & NA & 8.7 \\
\hline
\end{tabular}


Table 2 Organic P, K, Mg and Ca in primary and secondary sludge

\begin{tabular}{lll}
\hline & Primary sludge & \\
& & Biomass $^{(\mathrm{b})}$ \\
\hline $\mathrm{P} \quad(\mathrm{mgP} / \mathrm{mgTVS})$ & 0.0130 & 0.0200 \\
$\mathrm{~K} \quad$ (mgK/mgTVS) & 0.0028 & 0.0080 \\
$\mathrm{Mg}$ (mgMg/mgTVS) & 0.0050 & 0.0040 \\
$\mathrm{Ca}$ (mgCa/mgTVS) & --- & 0.0040 \\
\hline
\end{tabular}

(a) Experimental data from the fermentation/elutriation pilot plant

(b) Metcalf and Eddy (1995) 
Table 3 Potassium, phosphorus, magnesium and calcium balance in the digester for both experiments

\begin{tabular}{lll}
\hline Parameter (mg/l) & Experiment A & Experiment B \\
\hline K$_{\text {TOTrel }}$ & 196.0 & 66.7 \\
KORGrel & 61.7 & 62.8 \\
KPAOrel & 134.3 & 3.9 \\
PAOrel $_{\text {PORGrel }}$ & 379.5 & 11.1 \\
P $_{\text {TOTrel }}$ & 182.7 & 186.9 \\
Pprec $_{\text {Mg }}$ & 562.1 & 198.0 \\
MgOrel & 460.9 & 229.0 \\
MgORGrel $_{\text {TOTrel }}$ & 47.9 & 3.1 \\
Mg$_{\text {prec }}$ & 155.3 & 49.4 \\
CaORGrel & 189.9 & 52.5 \\
Ca & 24.2 & 68.4 \\
\hline
\end{tabular}


Table 4 Crystallizer influent characteristics

\begin{tabular}{lll}
\hline Parameter & Liquor A & Liquor B \\
\hline $\mathrm{P}_{\mathrm{T}}(\mathrm{mg} / \mathrm{l})$ & 156.5 & 53.4 \\
$\mathrm{PO}_{4}-\mathrm{P}(\mathrm{mg} / \mathrm{l})$ & 148.6 & 43.0 \\
$\mathrm{NH}_{4}-\mathrm{N} / \mathrm{PO}_{4}-\mathrm{P}$ & 7.9 & 6.7 \\
$\mathrm{Mg} / \mathrm{P}$ & 1.0 & 1.5 \\
$\mathrm{Ca} / \mathrm{P}$ & 0.3 & 2.3 \\
$\mathrm{Ca} / \mathrm{Mg}$ & 0.4 & 1.6 \\
\hline
\end{tabular}


Table 5 Crystallization process results

\begin{tabular}{lll}
\hline & Liquor A & Liquor B \\
\hline Operational conditions & & \\
\hline Liquor flow-rate (l/ h) & 1.7 & 1.7 \\
$\mathrm{pH}$ & 8.7 & 8.7 \\
\hline Removal & \\
\hline $\mathrm{P}_{\mathrm{T}}(\mathrm{mmol} / \mathrm{l})$ & 4.24 & 1.31 \\
$\mathrm{PO}_{4}-\mathrm{P}(\mathrm{mmol} / \mathrm{l})$ & 4.37 & 1.15 \\
$\mathrm{NH}_{4}-\mathrm{N}(\mathrm{mmol} / \mathrm{l})$ & 5.18 & 0.42 \\
$\mathrm{Mg}^{+2}(\mathrm{mmol} / \mathrm{l})$ & 3.17 & 0.41 \\
$\mathrm{Ca}^{+2}$ (mmol/l) & 0.25 & 1.47 \\
\hline Phosphorus removal efficiencies & \\
\hline Precipitacion efficiency (\%) & 91.1 & 83.1 \\
Recovery efficiency (\%) & 83.9 & 76.0 \\
\hline \multicolumn{2}{l}{ Struvite obtained } & \\
\hline P-MAP (\%) & 72.6 & 35.4 \\
\hline
\end{tabular}

